\title{
FEELING SOME TYP'A WAY: A YOUNG BLACK WOMAN'S EXPERIENCE OF EDUCATION IN SOUTH AFRICA
}

\author{
N. Shabalala \\ Department of Psychology \\ Stellenbosch University \\ Stellenbosch, South Africa \\ e-mail: shabalala.ncn@gmail.com
}

\section{ABSTRACT}

This article aims to contribute to conversations about Black subjectivity by engaging with the reflections of a young, Black, female student at Stellenbosch University. An auto-ethnographic approach is used to demonstrate the complexity of inhabiting multiple intersecting identities. I also explore the internal battles that I have faced and how I constantly negotiate my Blackness. The narrative shows a journey through education while highlighting socio-economic and emotional factors that may contribute to how education is experienced in South Africa.

Keywords: Black subjectivity, auto-ethnography, cultural hybridity, education

\section{INTRODUCTION}

“Feeling some typ’a way”.

When I walk around Stellenbosch, particularly areas closest to the university, I immediately feel some typ'a way (type of way). Now, I could put it differently, but I cannot fully articulate the feeling, and all I know is that it is uncomfortable. When I tried to describe this feeling to my (White) supervisor when he asked me what it meant, I was tempted to say, "nobody knows, but it's provocative" ${ }^{1}$ which is true, but I thought that was enough hip-hop for one session. Shelbe $(2013,16)$ describes some typ'a way as a set of strong, complex feelings mostly associated with anger, disappointment and sadness. There are undoubtedly many factors that predispose me to feeling this way within that setting, however, what interests me is the internal dialogue that takes place as soon as I set foot on campus and how I manage issues of difference.

I am currently pursuing my Ph.D. at Stellenbosch University. My study focuses on the experiences of Black medical specialists in training at two universities in the Western Cape. The process has been emotionally evocative for me because I am constantly confronting my complex positioning as a young Black female psychologist. For example, I represent the small portion of Black students who have been fortunate enough to have easier access to education I have gained a lot from policies such as affirmative action. However, our country's traumatic 
history (which I have not experienced directly) still seems to carry some weight in terms of my day-to-day experiences. I have experienced wanting to fit in to a setting where there are only a few Black people, and I would try as far as possible to assimilate to the context while attempting to preserve my Blackness. As a result, I embody “different shades of blackness” in different situations and contexts (Maodzwa-Taruvinga and Msimanga 2014, 2061). Changes in theory over time have led to more contemporary understandings of culture. Emphasis is placed on how cultural identifications are porous and ever-changing. People may inhabit multiple, and at times contradictory, cultural positions simultaneously and these may change in different situations (Swartz 1998). Developing understandings of how people are positioned is important. It is particularly important to engage with how multiple positionings work together to influence the experience of Black people. The article looks at moments where I have had to negotiate whether I stand in solidarity with my fellow Black people or if I dare to have a differing opinion. Maodzwa-Taruvinga and Msimanga (2014) discuss what they have conceptualised as processes of essentialising the Black experience and differentiating the Black experience. Their experience of being foreign nationals and academics at a South African university highlights moments where they were expected to stand in solidarity with other Black academics in challenging structural inequalities faced within higher education while at times being excluded by local Black academics because of perceived preferential treatment given to foreign Black academics by Whites Maodzwa-Taruvinga and Msimanga (2014, 2060). They described this experience by making an analogy of a swinging pendulum, which resonates with me. I have often felt ambivalent about where I fit in, as there have been times where I have felt excluded by other Black people because of the schools I have attended or how I spoke English.

In this article, I discuss the complexity of my own positioning, using an autoethnographic approach and tracing my own history. Parts of this article may make for uncomfortable reading, which is to be expected with employing an auto-ethnographic approach. This is in line with the emancipatory discourse feature of auto-ethnography where I am allowed to say the "unsayable" (Richards 2008, 1722). I choose to speak about emotion in as candid a way as possible as Richards (2008) has suggested. It is also in an effort to challenge dominant discourses that have, in the past, served to marginalise certain groups of people (Gough 2015). This approach also allows for a richer description of the individual experience and makes it possible for certain assumptions about the human experience to be interrogated (Richards 2008). One of the features of contemporary academic writing in auto-ethnography is that it disrupts the conventions. Jones $(2016,229)$ highlights that the "critical” feature of critical auto-ethnography teaches us that theory is not a "static and autonomous set of ideas". He further explains that theory and storytelling constantly influence each other. Critical autoethnography commits itself 
to a collaborative dance between theory and storytelling and allows us to engender and embody change (Jones 2016, 230). Some queer theory is discussed in Jones (2016) as he highlights how its disruptive nature influences the style of writing that is found in critical auto-ethnography. The format of the article and the style of writing employed is unconventional and at times informal, which is in line with critical auto-ethnography.

\section{SETTING THE SCENE: EARLY DEVELOPMENT AND PRIMARY SCHOOL}

I was born, and lived, in a township for the first 11 years of my life. As semi-dramatic as that opening line is, I have no horror stories about growing up in the township. Despite resources being limited and being raised, at the time, only by my mother, I was happy and healthy. I cannot say I have experienced apartheid, nor did I grow up hearing traumatic stories about it. However, there would be passing comments about White people that I would pick up when the adults were talking and they were never positive. I went to a multi-racial crèche in 1993, and in 1996, I started grade 1 at a predominantly White school. In earlier years, some Black children would have to repeat grade 1 or 2 because of their lack of proficiency in English. I asked my mother once how it happened that my cousin, who was two years older than me, was in my class, and she explained that he still had to improve his English. I travelled out to school every day by bus with my mother, but there was a school directly opposite to where I lived. At times, I would wonder why I had to wake up so early to get to school when there was a school less than five minutes away. I soon got the sense that I was in a privileged position, and fortunate that my mother could afford me better education.

Walking from the bus station to my house was anxiety provoking. I did not like having to get home when the school children from the school opposite my house were still around. There was a sense of animosity I felt from them, I was always teased for being small, for being scared and for going to a former Model C school. Some children in my street went to predominantly Indian schools, so I also did not really relate to them either. I became very aware that the education that I was afforded was better and that it took a lot of sacrifice from my mother.

I coped well academically, and my mother was able to assist me with homework when I needed it. What was difficult was the compulsory extra-mural activities and sports, at least one of each, as was stipulated in the school rules. I dreaded swimming because it always felt like I was drowning, and as a result I hated physical education (PE) in summer. After school, I played hockey (while most of the other Black girls played netball) and I liked it, but this meant I would have to get home late because I would miss my regular bus. At times my mother would try to organise for me to get picked up by my uncle or a relative because we did not have a car at home. Practice was compulsory, and so were games. I, like many other children that lived far 
from school and whose parents did not have cars, knew that we would have to pressure our parents to find a way for us to be there or we would have to suffer the consequences; being demoted, benched or even detention.

When I was in grade 6, my mother and I started looking at high schools. She considered where I wanted to go; we also explored fees and the distance from home. It dawned on me at that point that education was directly linked to finances. After many conversations, my mother and father agreed that I would live with him and attend school where my half-sister was. I went to an all girls' private school; it was a traditional Anglican school and at the time with very few Black girls. It was a relatively small, conservative school with a strong Christian ethos. A sense of community and fellowship was encouraged, however in my second year of high school (standard 7) the grade went into what psychologists call a storming phase. We were less cohesive, and as Black girls we became defensive. Because we represented the minority, as Black girls we stuck together, and we had a sense of familiarity that comes with speaking the same language. However, we noticed that the White girls would become suspicious of us when we spoke in Zulu. Although it was not an official rule, we were discouraged from speaking Zulu during school hours as it was considered rude to others that did not speak the language. It felt like we were fighting a losing battle at a point, but we shied away from calling it discrimination or racism. I know I felt quite ambivalent about racial dynamics when others felt strongly about our right to speak our language as it came naturally to us, and we were not doing it to exclude anyone.

The tension became very apparent during school camps where we would group ourselves on the bus and in the dormitories. The teachers, again, would discourage us from speaking Zulu and we obliged. When they were not looking, we would do so deliberately and loudly to the annoyance of our White classmates. I felt that I had to stand in solidarity with my fellow Black girls, especially because I did not want to be considered a traitor, but I also did not want to rock the boat with the teachers. We had two Coloured girls, four Indian girls, and we were six Black girls out of a grade of 52. Girls of colour were out-numbered; the Black girls felt ostracised, the Indian girls' silence was deafening, and the Coloured girls did not know which side they fell on. Despite noticing the tension, the teachers did not do anything, until one night a racist comment was made by one of my White classmates after being frustrated with our deliberate defiance. We immediately stopped talking and confronted her, which brought her to tears. I was infuriated, and that night I was no longer ambivalent. After camp, we were sent to the school counsellor who tried to reunite the grade again. We protested and asked why it was acceptable for the Afrikaans girls to speak their home language at their leisure while we were shamed for speaking ours. We were told that the majority understood English and Afrikaans, and we would 
have to comply with the ruling.

After some time, we lessened the use of Zulu when in the presence of our peers and things seemed to normalise until we had to choose subjects going into grade 10 . We were told that English 1st language and Afrikaans 2nd language were compulsory, and we were free to choose all other subjects guided by the aptitude test we took and feedback from our teachers. Only one learner in our class was exempt from doing Afrikaans, and this was because her primary school education was not in South Africa, so she could do French or German as an alternative. French was a subject that was offered by the school, but if she elected to do German, she would have to get a private teacher in and still get her full credit. I did not think anything of it, as I was competent enough in Afrikaans and it was how things were. However, my comfort with taking Afrikaans was not shared by three of my fellow Black girls. My best friend was also competent in Afrikaans, but felt that if an exception could be made for an international student (as she would not be competent in the language), why was the offer not extended to the Black girls that struggled with Afrikaans. She further pointed out that some schools, including those on the Independent Examination Board syllabus like ours, had the option of taking and being examined in Zulu as an alternative to Afrikaans.

The responses from the headmistress and the grade head varied from, but we chose to go to that school knowing what the curricula structure looked like; to the school does not have the capacity to offer this; to those girls being looked at as if they were antagonists. Eventually they were told that if they found their own teacher, and paid privately, they would be able to take Zulu as a second language instead of Afrikaans. I felt anxious and ambivalent again, I knew that I would struggle with Zulu, as I had not taken it as a subject before. I lived in the boarding establishment, so I would not have my parents to help me either. I knew I would not fail, but Zulu literature would be challenging. I decided not to drop Afrikaans, but felt that I was missing out on an experience, and to an extent I felt that my Blackness was diluted. For the rest of high school our grade seemed to repair the rupture and maintained pseudo-homogeneity.

\section{UNDERGRADUATE TRAINING}

During my undergraduate training, I was enrolled at the University of Pretoria (UP). Moving into my residence at university was exciting. I met my roommate, who was Coloured, and we bonded over being from Kwa-Zulu Natal. We both started noticing that Black girls were placed together, and similarly White girls. There was no other Coloured girl in our year, and they placed us together because we were from the same hometown (and only after checking with the Coloured girl's mother if that was alright). As weeks went by, we noticed that Black students formed a minority across disciplines and faculties on the main campus, while on the campus 
we lived in, the education campus, we saw more Black students. There was a men's residence closer to main campus that was allegedly only for Black male students, which had just closed, and those students were then reallocated across men's residences. The rumour going around was that the resources were poor at that residence and they had to find a way to house the male students without ruining the 60 per cent White/40 per cent Black policy at residence. It was very confusing as to what the actual housing policy was (although this could have been easily read up on) because of rumours that were spread around it. The rumour was that no more than 40 per cent representation of Black students would occupy the residence, and I, like many, believed it to be true. This made integration difficult; I gravitated towards Black and Coloured students and was wary of White, Afrikaans students, especially those who elected to attend Afrikaans lectures.

The rumours progressed gradually throughout my undergraduate studies. Some of my friends and I started to think that we had to compete with each other in order to be allocated into housing the following year, and to get into the honours programme. We believed that our race was considered before our capabilities. This pulled me further away from White students, but I also secretly hoped that my marks were among the top achieved by Black students in order to secure my place. It was a confusing time for me; there were some White students (predominantly English) that I got along with, and I was a good student but felt not good enough. It felt a little like “culture shock”.

This made my journey through anthropology more interesting as we were discussing ideas relating to culture, race and South Africa. The professor was talking about culture and race in post-apartheid South Africa. Although I cannot quite remember what he asked, I remember describing how I had experienced culture shock during my undergraduate studies at that university because racial discrimination seemed so blatant. Having briefly forgotten about my grade 9 year, and the difficulty some learners faced with Afrikaans, I described coming from a tolerant, conservative all girls' school that believed in unifying us. I described being shocked at the racial tension at UP. The professor asked if every part of me as a Black girl was embraced at my high school, or whether I had to assimilate to gain that tolerance. Memories of some of the difficulties I had faced in my education up until that point flooded. I remembered the helplessness I felt as a township girl, the anger I felt in grade 9 and the ambivalence I felt when I chose to do Afrikaans instead of Zulu. I soon realised that, as a Black female, my position was far more complex.

\section{POSTGRADUATE STUDIES}

In my honours year as a psychology student things were even more competitive. The class had 
shrunk considerably, and we were aware of how difficult it would be to get into a master's programme. At this point the White students were so aware of our supposed powerful position, where we were likely going to be chosen over them because of being Black and, in my case, female. This gave me a sense of comfort, but I also did not like the undertone of what was being said. It felt to me like my potential and academic progress was being undermined by the quota system. I appreciated that more women of colour were getting opportunities, but I also wanted to be recognised for the hard work that I had put in up until that point.

I applied to two programmes, master's in research psychology and master's in clinical psychology. I was reluctant to apply for clinical psychology due to horror stories I had heard about the selection process. My true intention was to apply at Stellenbosch University because I did not think I would get into an Afrikaans institution, and would finally get a chance to take that gap year. I also thought I would not get in because I was too young. To my surprise, I was shortlisted and invited to the selection process where I was cautiously optimistic. The selection process was anxiety provoking, and feelings of being out of my league set in. However, I got through the week, and by the end of that week learned that I was selected. I was very excited and definitely shocked. I sent a message to a friend; let us call her Phumla, who was in the honours class with me to inform her of the good news. In excitement, she shared the news with our class. She conveyed the congratulatory messages, but she also informed me that some of the White girls in our class then made a comment about me getting in because I am Black. I was so disappointed to hear this, and although I was proud of myself, I could not help but wonder to what extent this was true or rather how much of me being Black swayed the decision to admit me into the programme.

A fraction of us received placement invitations with the majority of those being invited into the research programme. I was the only Black student in my class that made it into a clinical programme, and I felt somewhat ostracised by my peers, both Black and White. Although I was always prepared and did well in my honours year, I carried with me doubt and anxiety as I went into my master's.

I had inspected the mailing list to see if I could spot another Black name, and I realised I was the only one. There were three Coloured people in our class, but in my head that did not count; I was the only Black person in the class and I was terrified. This reinforced ideas I had of being selected for the programme for the university to maintain a political correctness. When I met some of our lecturers and classmates, they all commented on how tiny I looked and how young I was, which made me feel even more out of place and inferior. This was not because of the reception at the programme, but rather my own insecurities. I was not sure I could compete at that level, and was horrified at the possibility of being that Black girl that was given an 
opportunity and failed. By the end of the orientation week we had been given readings that took up a quarter of my very small bachelor apartment. I felt so overwhelmed by Friday and regretted not taking that gap year. One of my classmates reassured me that we were all feeling the same way as we cried together. I appreciated her saying that, wiped my tears and was determined to work hard. I also irrationally thought that because I was especially selected for quota purposes, I could not give the department reason to regret selecting me. In the second week, we chose our community projects. These would form a large component of our final marks, and ran throughout the course of the year. We had heard a bit from each lecturer that supervised the placements, and from there we would choose which projects we wanted to do. One of the community projects was based in Kayamandi, a Xhosa community in Stellenbosch. As soon as the project was introduced my classmates looked at me, like it was a no brainer that I would go into that community. Before learning about what the placement was about, it felt to me like a decision was made for me despite us being told anyone could do whatever project. I asked myself, what if I was Setwana speaking, then what? I would still face some challenges. Fortunately, I liked what the project entailed.

I struggled a lot during my master's year; my academic writing skills still needed to be developed, and writing psychodynamic formulations seemed like a skill set way beyond what I was capable of. In retrospect, I had placed a glass ceiling over my head and my inferiority complex grew from task to task. I believed I was the only one struggling, because others' admission to the programme was based on merit, unlike me. My current academic mentor reassured me during research supervision that the department selected me on merit, and that even if the quota was a factor, it was not the only reason I was there. Some of my supervision sessions, both clinical and research, felt more like supportive therapy, which served to contain me for a bit. Despite feeling exposed, I pushed on. I was asked at point if I wanted to go on the two-year track, also because my research topic was considered too big for a mini dissertation. I was adamant that I wanted to stay on the one-year track. I had to prove that I deserved to be there.

Still determined to pass, the year went on and we were informed that we would have to apply for internship placements. We visited the hospitals that offered internship training to get a sense of where we wanted to apply. We were also told that spaces are limited at each of the placements, and I knew I had to get myself ready for yet another contest. Shortly thereafter, we were all invited to interviews at the placements. The first internship interview invitation was for a historically Afrikaans hospital that still caters for a mostly Afrikaans population. I remember asking my clinical supervisor if I would have to conduct psychotherapy in Afrikaans. She said no, but also indicated that the population was largely Afrikaans. Although I had a basic 
understanding and could speak some Afrikaans, I did not feel comfortable. The first thing that made me uncomfortable was the fact that I would not typically engage in a conversation in Afrikaans, and the second reason was how Afrikaans is spoken of by many Black people. It is largely associated with apartheid and I have heard reference to it being called "the language of the oppressor”, a language that was imposed on Black people.

I still went to the interview, somewhat distracted because I had to be back on campus later for a client. The reception was warm and not too intimidating; they explained that there was a representative from human resources to ensure that the process was fair and equitable. The interview was not too bad, for the most part, until they pulled up my application form and saw I indicated that my Afrikaans was poor. I purposefully indicated my proficiency in Afrikaans as poor, so that there would not be an expectation for me to speak Afrikaans. They highlighted what I had indicated, and I asked if it would be a problem. They said no, but cautioned about the expectations from some patients and asked how I would handle this. I responded and said, for the sake of rapport building, I would allow the patient to speak in Afrikaans, ask them to try to explain in English when I did not understand and would ask if I could respond in English. One of the interviewers then asked, “maar, hoe is jou Afrikaans?” I reluctantly responded in Afrikaans, "ek probeer maar net”. They all delighted at the fact that my Afrikaans was not as poor as I endorsed it to be, and the interviewer added that she could tell I had spent some time in Pretoria. Apparently, I spoke Afrikaans like they do in Pretoria - I ironically refused to speak in Afrikaans while I was in Pretoria. It felt as though a lot more time was spent on the language issue. It led to me thinking that in order to survive that placement, I would have to assimilate. I was not against assimilation per se (I was not that critical a thinker yet), I was afraid I would fail at it. I knew I was not comfortable consulting in Afrikaans. It was difficult enough trying to counsel adolescents in Kayamandi in Zulu; I could not imagine attempting to do so in Afrikaans.

In other interviews my language proficiency was highlighted in terms of what I could do. I took pride in being proficient in more than two languages: English, Zulu, Xhosa, and basic Setswana, but also started noticing the word "diversity" being thrown around. I started becoming very aware of that and became less comfortable with it, as it reinforced my fear of being hired solely on the basis of me being the diversity within the department. Here, I use this word ironcally to indicate that I represent a diversity in that I was a person of colour but in my experience I came to embody the whole enterprise of diversity - what I have chosen to call "being the diveristy". I would silently get angry when some lecturers would allude to what an asset I would be because of my race and language proficiency. My classmates would also comment, saying it should not be difficult to place me, almost as though I had no right to be 
anxious about whether or not I would get a placement. My experience of what was being said was not positive, regardless of whether it was meant to be or not. The recurring thought for me was: "I will never be taken seriously as a psychologist in South Africa". This goes back to what I mentioned earlier; that if I am chosen for equity's sake, I will never know if I am truly competent enough to be there.

I never spoke about my fear or anger, but expressed my anxiety about not being able to pass the year. They reassured me the best they could with the limited information I would give them in terms of my emotional experience. I started becoming very ill towards the end of the year with irritable bowels and migraines, which is consistent with being anxious. There were depressive moments, which I was reluctant to share for fear of exposure and I wanted to make sure the supervision frame was maintained. I got placement offers, and before I knew it we were preparing for our final oral examinations. For the first time, I spoke freely about how difficult my master's training was and how alone I felt at times. I had not planned to be so candid, but I felt they needed to know where I struggled and where I felt more support could have been given. I became very vulnerable during my oral, but I did not sit with any shame or guilt because I knew that was the end. Despite my difficulties, and perceived incompetence, I was one of five that graduated within the minimum required time, from a class of ten. I was very overwhelmed on graduation day and had the diarrhoea to prove it.

The following year I started my internship at a smaller hospital with a range of experience. I chose that placement because it seemed less intimidating and had more people of colour in the department than the other sites. As interns, we had a lot of autonomy with opportunities for learning to take place. I made a commitment to trust what I had learned, and myself. I also received positive reinforcement, which I was able to metabolise and gained some confidence. My research supervisor stayed in touch and he made a commitment to become my academic mentor. We soon started looking for opportunities to further my studies. I am not sure what he saw in terms of my potential, but for me it was an opportunity to gain more confidence. I thought pursing a Ph.D. would prove to me, and others, that I belong in that space. The thought of pursuing my Ph.D. contained my anxiety regarding what I believed others felt about my presence in the university, the master's programme and in the hospital.

The final phase of my training was my community service year. This is an initiative where the primary aim is to extend healthcare services to all South Africans, but more specifically in areas that were and still are underserviced. This was in response to many medical doctors and health professionals leaving the country after qualifying. The idea was for them to give back to the community for a year before pursuing their careers abroad or privately. This mandatory community service year also applies to clinical psychologists. I completed my community 
service at a township hospital where the racial demographics were more favourable, as in more Black people. I no longer felt a sense of being under constant surveillance or scrutiny. I had less supervision, and relied on some of my colleagues for feedback on cases, but I felt an incredible sense of confidence. Our department was made up of a few psychologists; two of us were community service psychologists. We had one White, Afrikaans female psychologist who seemed to mirror some of my experience in Stellenbosch. She and I became good friends and often spoke about issues of race and belonging, with me being more curious than she was. What struck me about her was that she seemed to have an ability to take the context in her stride. I used to wonder if she felt any discomfort, and if she did, how she handled it.

We had a discussion about her experience, because I was very curious to hear if her experience indeed mirrored mine. She told me that she was aware that she was different and that at times would need to compensate for that difference. She expressed that she felt a need to work hard to challenge stereotypes relating to Afrikaans people in our country. As an Afrikaans woman, she expressed being quite sensitive to the legacy of racial segregation, but also feeling as though she did not want to be held hostage or overcompensate for who she is. I remember being quite envious of her ability to distance herself emotionally and, sometimes in the face of cultural discomfort, physically. I did not know how to do that; I did not know how to not take the discomfort on. It seemed to me that she had a certain security about her identity that I did not possess.

I became increasingly motivated to do my Ph.D. in order to start exploring Black subjectivity. Shortly after registering as an independent practitioner, I moved to Stellenbosch to pursue my Ph.D.. My mentor told me about two projects that he is involved in; although he had given me an option to choose one that resonated the most with me, he also had an idea as to what I would gravitate towards. I chose a project under the auspices of the Harambee organisation. The Harambee organisation is a non-profit organisation of Black medical specialists. The overall project conducted by the Harambee organisation aims to improve and enhance healthcare systems in South Africa through the investigation and evaluation of race as a potential factor that pertains to outcomes in medical specialist training. We are interested in patterns of overt and covert exclusion of Black people from what has historically been a White enterprise (the practice of medicine in South Africa) (Thackwell et al. 2016; Thackwell, Chiliza and Swartz 2017). This sounded like an important project, but the other motivation was that I would have an opportunity to work with and learn from people that look like me and are professionally successful. Not only had they succeeded, but they were each respectable in their own right. Being in a room with these Black specialists, despite them all being male, gave me a sense of hope. I could see that they were respected, and in terms of my subjectivity, that 
opened up the possibility of being respected within my field as a Black professional. This is also due to the fact that I had direct contact with these professionals which opened up an opportunity for mentorship to take place. As highlighted in Thackwell et al. (2017), mentorship has been seen as one of the important factors for success and career advancement of junior professionals.

\section{ON BORROWED PRIVILEGE}

When exploring race as potentially one of the determining factors when it comes to throughput rates, it lends itself back to the legacy of apartheid education and racial discrimination under apartheid. Having to engage with transformation literature and, inevitably, with the past, remains one of the most difficult and emotionally taxing tasks of my study. As previously mentioned, I was familiar with South Africa's apartheid history, but I have no memory of living in those times because I was too young. However, reading up on it for my literature review and having to consult multiple sources that outline the history continues to make me feel very uncomfortable and relatively angry. I feel angry at the injustice of what many of my Black forebears had to endure and at the contemporary legacy. In terms of schooling and access to better education and opportunities, I have been very fortunate. I feel that I now need to evaluate my position and be critical about what constitutes that privilege. There are a few things that I find problematic with this borrowed privilege, and I frame it that way because it appears to have a "terms and conditions apply" disclaimer. As a result of this privilege, I do not have a clear sense of my Blackness, a sense of security in my Blackness. I do not wish to essentialise here, but in my experience it feels important to me to have an understanding of who I am as a Black person and not to hide or deny what I experience to be an important part of my identity which is often effaced in the professional context. I have not quite figured that one yet; it feels as though I have been accultured in a direction that seems to demand that I dilute my Blackness in order for me to belong. Fanon suggests that maybe the solution is to assert myself as a Black person and to not go through life having to overcompensate for being Black:

"I resolved, since it was impossible for me to get away from an inborn complex, to assert myself as a Black man. Since the other hesitated to recognize me, there remained only one solution: to make myself known.” (Fanon 1952/1986, 115).

I have been less aware of when and how I move in and out of my Blackness before, but now I have the understanding that my identity as a Black woman is constantly being negotiated within different contexts. So, I wonder what the implications of this are; am I to accept the new kinds of marginalisation such as issues of access into higher education and healthcare disparities that 
take place because I have been so privileged or do I join the Fees Must Fall movement that challenges issues of access, race and the socio-economic divide (see Davids and Waghid 2016)? This may appear to be a self-indulgent question but it is not an unimportant one because within the context of the experience of many Black professionals, I come from privilege. It's complicated; it's confusing and uncomfortable. A part of me wondered if I had a right to talk about certain injustices, like issues of access into higher education institutions, when my experience has been fairly smooth, but maybe it is true that "the way out of a problem is to be conscious of the problem” (Mamdani 2012, 91), and perhaps that's the starting point for me.

\section{CONCLUDING THOUGHTS?}

I would like to be able to sum this all up neatly, but I feel in a state of deep ambivalence and I continue to feel this way. As I articulate this, my question really is (and I am not in the position to answer): is this just my ambivalence or is it part of a bigger picture? The work of MaodzwaTaruvinga and Msimanga (2014) seems to suggest it is part of a broader context, but I have written this article partly in the hope to open up a discussion about the complexity of race, which I have experienced quite deeply, within the academy.

\section{NOTE}

1. A script line from the movie Blades of Glory sampled and made popular by a song by Jay-Z and Kanye West.

\section{REFERENCES}

Davids, N., and Y. Waghid. 2016. \#FeesMustFall: History of South African student protests reflects inequality’s grip. Mail \& Guardian. http://mg.co.za/article/2016-10-10-feesmustfall-history-ofsouth-african-student-protests-reflectsinequalitys-grip (Accessed 29 June 2017).

Fanon, F. 1986. Black skin, white masks. Translated by C. L. Markmann. London: Pluto Press. Original work published 1952.

Gough, B. 2015. Qualitative methods: Critical practices and prospects from a diverse field. In Handbook of critical psychology, ed. I. Parker, 107-116. Sussex: Routledge.

Jones, S. 2016. Living bodies of thought: The “critical” in critical autoethnography. Qualitative Inquiry 22(4): 228-237.

Mamdani, M. 2012. Define and rule: Native as political identity. London: Harvard University Press.

Maodzwa-Taruvinga, M. and A. Msimanga. 2014. Contradictory location of the Black woman passport academic: Embrace, alienation and vulnerability. South African Journal of Higher Education 28(6): 2052-2064.

Richards, R. 2008. "Writing the othered self: Autoethnography and the problem of objectification in writing about illness and disability. Qualitative Health Research 18(12): 1717-1728.

Shelbe, L. 2013. Some type of way: An ethnography of youth aging out of the child welfare system. Ph.D. dissertation. http://d-scholarship.pitt.edu/19159/

Swartz, L. 1998. Culture and mental health: A Southern African view. Cape Town: Oxford University 
Press.

Thackwell, N., L. Swartz, S. Dlamini, L. Phahladira, R. Muloiwa and B. Chiliza. 2016. Race trouble: Experiences of Black medical specialist trainees in South Africa. BMC International Health and Human Rights 16(31): 1-6.

Thackwell, N., B. Chiliza and L. Swartz. 2017. Mentorship experiences during registrar training: Reflections of Black African specialists in the Western Cape. Race, Ethnicity and Education: 118. 